https://doi.org/10.48009/1_iis_2010_577-584

\title{
AFFECTIVE COMPUTING: INVASIVE TECHNOLOGY AND LEGAL CONSIDERATIONS TO PROTECT CONSUMERS
}

\author{
Lee Jonathan Steen, Robert Morris University, ljsst8@ mail.rmu.edu \\ Philip Kim, Walsh University, pkim@ walsh.edu
}

\begin{abstract}
The rapidly advancing fields of medicine and technology are converging, creating new capabilities and products that could not have been conceived of 10 years ago. One new field of study that has come from this convergence is affective computing. This field of study attempts to give machines the capability of understanding, feeling, and responding to human emotions. For some, a machine that can understand and respond to their emotions can be scary, invasive, disturbing, and even harmful. Many of the devices with these capabilities are still in infancy, but it will not be long until these devices become common place. The problem is that the laws in the United States do not address any of the potential problems that these devices will bring to light. This paper discusses some issues that these devices will bring about and present some solutions to the issues.
\end{abstract}

Keywords: Affective Computing, Media Equation, Human Computer Interaction, Invasive Technology, and Privacy.

\section{INTRODUCTION}

The rapidly advancing fields of technology and medicine are coming to a convergence. One new field that has been created is "Affective Computing." Affective Computing is defined by Picard (1997) as "computing that relates to, arises from, or deliberately influences emotions" (p.3). Affective computing is comprised of two major components of study. The first component is creating machines to have the ability to identify, recognize, and understand human emotions. The other is to provide machines the ability to actually feel human emotions. While engineering machines to "feel" emotions is still years away, the ability for machines to understand and respond to human emotions has already arrived.

For some people, machines that can detect, understand, and respond to their emotions is frightening, but for others this capability is exciting. Affective computing has mostly been studied around Human Computer Interaction (HCI) because computers with affective and emotional capabilities are expected to improve overall human-computer-interaction (HCI) (Goodwin \& Picard, 2008; Norman, 2002, 2004; Picard, 1997; Thagard, 2005). Researchers have theorized that computers with these capabilities are also needed to move the field of artificial intelligence (AI) forward and break new ground (Hawkins \& Blakeslee, 2004; Minsky, 2006; Norman, 2004; Picard, 1997; Thagard, 2005). Giving traditional AI machines a new ability to understand and respond to human emotions can be the most worrisome aspect of affective computing.

Theories about the future of affective machines, or machines that have affective computing capabilities are seen in mainstream media. Movies like Artificial Intelligence, The Terminator, Robocop, and Bicentennial Man, or television shows like Battlestar Galactica, Star Trek, and many others have provided examples of what the future of AI-based robotic devices can look like. Humans have a fascination with attempting to create life in our own image (Herzfeld, 2002). Further, Reeves and Nass (1996) have identified the Media Equation, which states that people will treat media like they would another person (Reeves \& Nass, 1996).

The media equation is the linking theory between creating machines that can identify and respond to human emotion and HCI. The media equation, in short, that people will treat media (e.g. computer) just like they treat other people (Reeves \& Nass, 1996). The media equation identifies that the human will treat and think of the computer device as another person. The human in the interaction applies anthropomorphic traits to the computer by giving the computer human traits that do not really exist in the computer (e.g. feelings). As an example, envision a person who has been working diligently on a file that resides on a computer, only to have the computer crash and lose all of the work. Naturally, the person becomes upset at the outcome, but can also exhibit direct anger at the 
actual device (computer) for losing all their work. Another example is of a child playing a video game and is not performing well within the constructs of the game. The child will yell at the game system and television, and some will even claim the video game "cheated." A final example is when people purchase a new PDA or smartphone device and "fall in love" with the object. They carry it with them everywhere and care for it as they would a child or pet. One might think they love the abilities, such as having the ability to surf the internet or send and receive emails, more than the actual device but many of those same people will still bring the phone with them in areas where no service is available.

Reeves and Nass (1996) have done several other studies that support the media equation and applying human to human communication techniques to computers. These studies included identifying televisions with personality, selecting computers based on perceptual bandwidth, and feeling empathetic toward computers (Nass \& Moon, 2000; Nass, Reeves, \& Leshner, 1996; Nass \& Steuer, 1993; Reeves \& Nass, 2000). This may be part of the reason why humans have such affection for created intelligence. Goleman (1995, 2006) identified that emotional and social intelligence are extremely important for human to human interactions. Further, Goleman (1995) identified that emotions can have a true physical impact on humans. This explains why humans are more likely to accept a computer that can understand and respond to human emotions. If a computer system can validate a person's emotions and feelings, the person is more likely to believe in the overall experience that the intelligent computer is real.

In a panel discussion led by one of the authors (Steen, 2009) about the moral and ethical implications of such affective devices, participants were asked about their feelings on several affective devices. These devices and their applications are discussed in the next section along with the issues affective devices are bringing out currently and what they could be in the future. These issues provide the necessary justification for new laws to be considered. The paper concludes with possible laws to base affective device legislation from.

\section{CURRENT AFFECTIVE COMPUTING APPLICATIONS}

At the beginning of the aforementioned panel discussion, participants were asked what they knew about affective computing, affective devices, and current applications of affective computing. Overall, 18 people participated in the panel discussion either during the panel discussion time or afterwards in informal groups. Only six people had an idea of what affective computing was, but their understanding was primarily in a general and abstract sense. Most people thought affective computing was "effective computing" at first, until they were told the first word is affective. Then, about half of the people took a guess at what it was, but still did not fully understand it. But once it was explained to them, many people were surprised that this research exists. Then, most of them were surprised when seven current and two future affective devices were explained to them. The responses varied from excitement, fear, anger, confusion, frustration, and joy. This paper only presents three of the devices that were the most concern for the participants.

The first device that is recognizable for most people to start to understand affective computing is the polygraph. The polygraph is commonly known as a lie detector. A polygraph machine measures a physiological change in a person, meaning the person is having a physical reaction to a mental thought. Polygraphs have been historically used to detect deceit. This means when a person is asked a question and a certain physiological reaction is detected; the person is having a mental problem with the question. The physiological reaction that is detected is a combination of one or more of the following: a) an increase heart beat, b) galvanic skin response, c) blood pressure increase, d) blood volume change, e) facial expression changes including pupil dilation, f) change in respiration, and g) body movement (D'Mello et al., 2008; Kapoor, Burleson, \& Picard, 2007; Qi, Reynolds, \& Picard, 2001; Picard, 1997; Picard \& Daily, 2005; Reynolds, 2001; Scheirer et al., 2002). Many of these detections are not possible without the aid of the polygraph machine. Specialized software takes input readings from each of the reactive items that pertain to various bodily reactions and establish a baseline. During an interrogation, the machine will constantly feed this physiological feedback to the software and will identify all reactions, or baseline deviations, detected. These responses or baseline deviations can then be analyzed to determine the level of reaction the person has had during the examination.

The polygraph machines are used by many law enforcement agencies to aid in interrogations, or 
by intelligence agencies to grant clearances to people (Central Intelligence Agency, 2009; National Security Agency, 2009). The problem with polygraphs is that they only measure a reaction but cannot explain why the reaction happened; only that it did happen. It is up to the examiner to use other inputs to analyze the data to determine why the reaction occurred. For example, a person might have a reaction to a question about elderly abuse. This does not mean the person participates in criminal activity; it might just mean the person is very sensitive to this subject because an aging parent is ill. Another issue is that a person might not actually have a reaction to a question that is intended to determine of the person is intentionally withholding information. If an examiner asked a child molester if he did molest a child, the child molester may be able to respond "no" without any reactions. This is commonly seen in psychopaths who truly believe what they have done is not wrong, and thus, experience no reactions. This is the reason polygraph results are inadmissible in court rooms.

When the participants within this study were asked about polygraphs, all of them believed polygraphs for obtaining clearance for national security positions were a positive measure for ensuring accuracy. But only half of them believed a polygraph should be used for other employment positions like teaching, law enforcement, business, and government positions (although, all of them also believed a polygraph should be mandatory for congress and senate positions). When people were asked to provide further explanation of their opinion, most people said the use of the polygraph is acceptable for a position within national security, because national security or intelligence communities should have more stringent requirements than positions within private industry. A common reason stated was that national security personnel should have "nothing to hide." The responses varied among the respondents, but most felt that those who worked in private industries such as manufacturing, retail, and financial services would not benefit from taking a polygraph examination. An interesting finding however was presented to the panel with the option of polygraphing all K-12 teachers to determine if the teacher was a sexual predator. All the participants agreed it would be beneficial and some stated it "should definitely be required."

The possibility of polygraphing teachers can concentrate on specific items and not go outside of the scope of the topic. This line of questioning can be very invasive and personal for people to disclose regardless of their potential to be completely innocent or become child predators. In theory, the polygraph examination would take place before the person started teaching and questions could be asked to determine if there are any feelings of sexual arousal towards children under 18. Because of legal and ethical reasons, as well as labor union restrictions, this line of questioning would most likely not be possible, but within the panel discussion, it was noted that school-aged parents would support the use of polygraph testing for teachers.

The second affective device discussed is a wearable (Picard, 1997) or a computer device that a person can wear and is ultra portable. This device does not commercially exist, but the technology is readily available to create such a device. The device can be a camera mounted on eye glasses that connects to a portable computer that a person can conveniently keep in their pocket. The camera feeds images to the computer directed by where the person is facing. The computer contains special software that looks for human faces and can analyze facial expressions to determine a person's mood. The software is based on Ekman's (2003) research on identifying human emotions based on facial expressions. Ekman (2003) has discovered that many emotions can be detected by facial expressions but many times these expressions happen in a split second and may be difficult to detect unless a highly trained professional is looking for them. This means if a person looks away at any point during a conversation, or even blinks, she may miss the expression she is looking for. The wearable device in discussion is called Detection Expression (DE).

DE can be easily disguised and hidden from people but provide feedback to the person wearing it. The person utilizing the detection expression tool can then use the data to analyze how the interaction is going or even how the other person is feeling. A positive use of this technology may be in assisting those with expressive communication disorders, such as those with autism spectrum disorders. DE may assist the parent or caregiver to identify the needs and emotions of the impaired individual while circumventing verbal communication. It could be used by the parent of a non-communicative autistic child to aid the parent in more accurately identifying the child's feelings and emotions. It may also help the child identify how the parent 
feels towards them. Another application could be for relational issues, siblings, spouses, and family members can use DE to help them identify feelings and emotions. All of these can be helpful applications and in this hypothetical example, the parties involved are aware of the detection expression devices in use. But what about a car salesman who uses the device to help him sell a car to customers who are unaware DE is in use?

All salesmen are different, but the best car salesmen all seem to have a common trait that the salesman can relate to and understand his customers (Gladwell, 2007). One of the easiest ways to make a person feel heard is by understanding his or her feelings and emotions, or showing empathy (Goleman, 1995). Many salesmen might not be able to easily understand and read people, but with the aid of DE, they may be able to act the part. Ekman (2003) notes that many facial expressions happen very quickly and are often easily missed if attention is diverted. So if a consumer is searching for a new automobile and the car salesman is able to use DE tools, he can quickly determine the consumer's positive and negative responses to various traits of a vehicle, it may increase the chance of a sale. For example, the DE could tell the salesman that every time he mentions the crash test ratings and third row seating, the buyer quickly smiles a bit. This quick smile is not easily noticed, but DE can pick it up. The DE also picks up a slight disdain or frown for the color red. Further, when mentioning the poor gas mileage or tax and transfer fees, there is no analyzable response. Now, the salesman can keep focusing on the items the buyer likes, stay away from negative responses, thus giving him an advantage. But is this really fair to the buyer? The buyer may be trying to hide what he is looking for so he really gets a fair presentation of all of the available vehicles. The buyer may not want the salesman to know how he is feeling because the seller now has an advantage over the buyer in negotiating the price.

When the panel was presented with this device, only three people said it was "fair game" technology. The rest of the people said they would be upset and feel violated if such a device were used on them. But when presented with a similar situation, only replacing DE with another live person that is watching the entire interaction from a distance and giving feedback, all but five people said it would be fair game. This seems to indicate the presence of the machine can be upsetting people and not the actual detection the device brings. A similar scenario was given to the panel, except this time, the person detecting the facial expressions was right next to the salesman and the customer knew what was going on, all respondents thought this was acceptable. The respondents also noted that there was a lack of transparency in the DE technology. In that only one party knew it was being used. This seems to indicate it is not only the mere presence of the machine, but that it was hidden was a significant issue. The final scenario that was presented to people was that DE was in use and the person was aware of this. It was this scenario that all but three people (15 respondents) said it was fair use, but almost all noted they would not likely go to that salesman or car dealer if they knew it was being used.

These results indicate that people do not like machines to be present and used to gather information about a person, whether the machine is present or not. But most of the respondents felt it is okay to do it with the knowledge it is being done and not hidden. This may be similar to how people feel about talking on the phone and being recorded. Many people would be upset if they did not know they were being recorded during a phone conversation. But yet, most customer service units report during the call that the conversation "may be recorded for training and quality assurance purposes." Perhaps if the car dealerships use DE a sign that says "customers may be recorded as they look for vehicles to optimize and aid in the vehicle buying experience" it would not be an issue?

The last affective device this paper discusses is an artificial intelligent (AI) component that is used to aid a person in emotion regulation called a Computer-aided Active Support for Personal Emotion Regulation (CASPER). CASPER is an AI agent originally designed by Klein (1998) that incorporates active listening therapy (Gordon, 2000) provided by the AI agent that makes the user believe the computer is understanding of the user's feelings and the user has been heard (Reeves \& Nass, 1996). Active listening has long been a technique used by psychologists to help people in therapy and to teach married couples good communication skills. The theory behind active listening is that the communication channels between two people offer feedback and each person feels like the other person understands how they feel (Gordon, 2000).

Klein, Moon, and Picard (1999, 2002) deployed CASPER in an experiment where participants were recruited under the guise that video game 
testers were needed. Participants were told they would be playing a new video game and they were offering a top prize of $\$ 100$ to the person with the best score. This prize gave all participants a goal to achieve. What the participants did not know was that the game was set to freeze at random intervals, thus inducing frustration into the player (Bessiere et al., 2004; Lazar et al., 2006). This experiment involved a 3 (No CASPER, CASPER, Vent Condition) X 2 (Delay, No Delay) matrix. The No CASPER condition offered a simple survey after the first game and nothing else. The CASPER condition offered the same survey, but also offered a paraphrase to the user based on the user's rating of frustration. This was a dynamic component that offered empathy and sympathy in the form of on-screen text to the user. The Vent Condition offered the same survey and an unlimited textbox used to allow the user to vent feelings. The Delay Condition induced frustration and the No Delay condition was a normal game. The results support the Media Equation theory and also support that CASPER is successful in mitigating frustration. Interestingly, the results also showed that Venting Condition made user frustration the same or worse, and the No Treatment Condition made no difference.

One of the authors of this paper (Steen, 2010) reproduced the CASPER experiment with a 2 (No CASPER, CASPER) X 2 (Delay Condition, No Delay Condition) matrix. The initial results (not yet official) are also leaning towards supporting CASPER's validity and success. This provides stronger evidence that researchers are able to induce frustration, joy, and satisfaction in people using computers. This also supports the fact that computers can be used as temporary therapy agents when a person is distressed.

The implications of these findings once again have two sides. CASPER agents can be used to aid in mitigating user frustration if properly installed in software applications. This gives a real-time treatment to user frustration and can end up saving software companies money and retaining customers in the long run. The CASPER agents could also be used as temporary therapeutic devices to help patients who are upset and need immediate intervention until an individual can be present to provide assistance. However, it is possible that as the CASPER agents evolve, the need for an actual person to be present may go away entirely.

Volume XI, No. 1, 2010
The other side is that these devices can be used to manipulate people's emotions. A company may be able to intentionally cause a person to get excited about a product or service and cause the consumer to be irresponsible with their money. Or possibly intentionally cause user frustration and have it mitigated with a product that is being sold on the company's website. Admittedly, the use of excitement and impulse selling are being done now, however the use of machines to act like humans can be unsettling for people, especially if it is not known this is happening. Emotions are extremely difficult to intentionally illicit from people (Ekman, 2006).

Most people said they found it upsetting if CASPER was used and the true intention of the experiment was not known to them. Most people were more upset when they did not know CASPER was being used to manipulate emotions, for good or bad reasons. But again, it is difficult, if not impossible, to intentionally illicit emotions from people (Ekman, 2006); meaning CASPER is much less likely to work if its presence is known. It is almost like people watching a scary movie can become unafraid if they simply remind themselves "it is only a movie." With conscious thought, it is harder to allow natural reactions from the human primitive brain to take place (Goleman, 2006). This means the natural reactions that humans have evolved from and used to live can be impeded by conscious thought and awareness..

Once again people at the panel were presented with the different scenarios and CASPER. These scenarios included replacing a psychologist with a computer, an intervening computer for user frustration when frustration was detected, and a wearable computer that had a CASPER agent installed that talked to the person when their emotions seemed out of synch to their daily feelings. If CASPER were replaced by a human, meaning a machine replaced by a person, almost everyone agreed that this was okay. This is no different than what a psychologist does. Even when presented with the scenario that the psychologist was intentionally manipulating emotions, most people were okay with it. But when the psychologist was replaced by a CASPER agent, more than half of the people said they would not like it. This again seems to indicate the machine and the fact it is not known that the machine is manipulating emotions is an issue. A final scenario presented was having a person use CASPER and know that it is manipulating emotions. Many people were again a bit hesitant 
to use a machine to help them aid in emotion regulation, but said if they knew what it was doing, they would try it out.

With all three devices presented above and an understanding that there will be many more available in the future, it is apparent that more research is needed on the moral and ethical implications of affective computing devices. It is also important to keep laws up to date as these devices are released. Similarly as cellular telephones with cameras are being incorporated to laws about where they can be used, and where they can be brought into, affective devices should be considered in the same context. The next section discusses suggestions to laws that should be in place to protect people.

\section{FINDINGS}

The panel discussion (Steen, 2009) on several affective computing devices helped identify three major issues people have with affective computing devices.

The first issue was when the devices are used on someone without their knowledge. In all of the cases presented (Polygraphs, Detection Expression, and CASPER), people indicated that they wanted to know it was being used. In the case of polygraphs, it was specifically how it was being used, and not that it was being used.

The second issue was that a machine was present instead of a person. Most people were more upset when they felt the machine was being used on themselves and not on someone else. This was mitigated for most people when they knew the device was being used and what it was doing.

The third issue that most people agreed on was ownership of the data. Other devices not discussed in this paper are data intensive, as users continue to rely on information systems to hold their information, there is an extremely large amount of proprietary and confidential data being collected. Examples of this are healthcare and patient data that can be used to track a person's bodily chemical changes to trend depression, or to track physiological changes in a person to trend anxiety. Participants wanted to make sure this confidential data were secure (e.g. encrypted) and were only used for their own medical purposes.

These were the three main issues that were uncovered. There were other issues, but these were the most pressing ones, thus, the proposed laws that follow will cover these three issues. These proposed laws are intended to base themselves off of previous laws when newer technologies were introduced and also to allow for further research to be performed on affective computing in the future.

The first law that should be considered is people must to be notified when an affective device is being used on them. This means if the car salesman wants to use the device, he is obligated to tell his customers that it is in use or that the car dealership uses it. Or in the case of CASPER, software companies have to disclose that a CASPER agent is incorporated in the software. This will then let people make their own decisions if they want to use the services provided, or to opt out so software can essentially have an "off" button. This is also no different from "The federal Omnibus Crime Control and Safe Streets Act of 1968, 18 U.S.C. Sec. 2510" which prohibits the recording of telephone conversations because people can reasonably expect privacy on the phone. People can also reasonably expect privacy with their own emotions and should be informed when there is a possibility of invasion. So again, instead of hearing "[t]his phone call may be recorded or monitored for quality assurance and training purposes" a person might hear "[y]our emotions may be detected to provide you with the best possible vehicle purchasing experience."

The second law that should be considered is the limited use of machines for therapy in certain illnesses including depression, anxiety, and schizophrenia. More diseases can and should be listed, but these are diseases that need professional attention and usually have a high, at-risk population, but could be treated with a CASPER agent if necessary. What this law would protect against is companies writing CASPER agent software and selling it as a therapeutic alternative to professional help. While this may work in the future as affective devices become optimized, they are certainly not ready for widespread use and people need to be protected from companies who want to make a quick profit from it. The limited use should specify a time and frequency that these devices can be used in place of professional help. This does not mean limiting the consumer, but limiting the producer from advertising their product as such.

The third and final law is that all data from these devices should fall under HIPAA regulatory
Issues in Information Systems 
guidelines. Meaning that any affective device that records personal data should be kept private and confidential, and that the owner of the data is appropriately authorized to use the device. This law may conflict with the first law about notification of use affective devices. If a car salesman is using a device and collecting data on a customer, that data is not owned by the customer. But the first law has exceptions; just like recording a phone conversation has exceptions. In public or with consent, data collected from a person cannot be considered private. This is like taking photographs in public. The photographs cannot be sold with people in them without the persons consent, but they can be taken. The same is likely to be true with affective devices. They are legal to use in public, but the data cannot be sold and cannot be used against the person without knowledge first (in the case of using an affective device on a person).

\section{CONCLUSION}

Affective computing devices are starting to be released and will soon be spread into mainstream use. Just as cellular telephones inched their way into everyday use, affective devices are eventually likely to become as ubiquitous. Affective devices can be used for medical, mental health, and aiding with law enforcement as well many other purposes. Many of these purposes can have both positive and negative outcomes. The devices can be invasive in reading emotions but can also be great aids in helping others understand the emotions a person exhibits. In order to keep people safe and ensure confidentiality and privacy, the solutions presented in this paper should be considered and discussed as the affective computing capabilities evolve.

\section{REFERENCES}

Bessiere, K., Ceaparu, I., Lazar, J., Robinson, J., \& Shneiderman, B. (2004). Social and psychological influences on computer user frustration. In Bucy, E. P., \& Newhagen, J. E. (Eds.), Media access: Social and psychological dimensions of new technology use (pp. 91-103). Mahwah, NJ: Lawrence Erlbaum Associates.

Central Intelligence Agency. (2009). Application process - Central Intelligence Agency. Retrieved November 8, 2009, from the Central Intelligence Agency website: https://www.cia.gov/careers/applicationprocess/index.html\#Clearance.
Ekman, P. (2003). Emotions revealed: Recognizing faces and feelings to improve communication and emotional life. New York: Holt.

Gladwell, M. (2007). Blink: The power of thinking without thinking. New York: Back Bay Books.

Goleman, D. (1995). Emotional intelligence: Why it can matter more than IQ. New York: Bantam.

Goleman, D. (2006). Social intelligence: The revolutionary new science of human relationships. New York: Bantam.

Goodwin, M. S., \& Picard, R. W. (2008). Developing innovative technology for future personalized Autism research and treatment. Autism Advocate, 50, 32-29.

Gordon, T. (2000). Parent effectiveness training: The proven program for raising responsible children. New York: Three Rivers Press.

Hawkins, J., \& Blakeslee, S. (2004). On intelligence. New York: Times Books.

Herzfeld, N. L. (2002). In our image: Artificial Intelligence and the human spirit. Minneapolis, MN: Augsburg Fortress.

Klein, J. T. (1998). Computer response to user frustration. Unpublished master's thesis, Massachusetts Institute of Technology, 1998.

Klein, J., Moon, Y., \& Picard, R. W. (2002). This computer responds to user frustration. Interacting with Computers, 14, 119-140.

Klein, J., Moon, Y., \& Picard, R. W. (1999). This computer responds to user frustration. Proceedings of Computer Human Interaction (CHI'99) late-breaking results, Pittsburgh, PA, 242-243.

Lazar, J., Jones, A., Hackley, M., \& Shneiderman, B. (2006). Severity and impact of computer user frustration: A comparison of student and workplace users. Interacting with Computers, 18, 187-207.

Minsky, M. (2006). The emotion machine: Commonsense thinking, artificial intelligence, and the future of the human mind. New York: Simon \& Schuster.

Nass, C., \& Moon, Y. (2000). Machines and mindlessness: Social responses to computers. Journal of Social Issues, 56(1), 81-103.

Nass, C., Reeves, B., \& Leshner, G. Technology and roles: A tale of two TVs. Journal of Communication, 46(2), 121-128.

Nass, C., \& Steuer, J. (1993). Voices, boxes, and sources of messages: Computers and social actors. Human Communication Research, 19(4), 504-527. 
National Security Agency. (2009). Hiring requirements for the National Security Agency (NSA). Retrieved November 8, 2009, from the National Security Agency website: http://www.nsa.gov/careers/jobs_search_apply /hirerequire.shtml.

Norman, D. A. (2002). The design of everyday things. New York: Basic Books.

Norman, D. A. (2004). Emotional design. New York: Basic Books.

Picard, R. (1997). Affective computing. Cambridge, MA: The MIT Press.

Reeves, B, \& Nass, C.I. (1996). The media equation: How people treat computers, television, and new media like real people and places. Cambridge, MA: Cambridge University Press.

Reeves, B., \& Nass, C. (2000). Perceptual bandwidth. Communications of the ACM, 43(3), 65-70.

Steen, L. J. (2009). Ethics and responsibilities of Affective Computing researchers. Panel discussion led at the Information Systems Educators Conference. Washington, DC.

Steen, L. J. (2010). Unpublished doctoral dissertation, Robert Morris University, 2010.

Thagard, P. (2005). Mind: Introduction to cognitive science $\left(2^{\text {nd }}\right.$, Ed.). Cambridge, MA: The MIT Press. 